\title{
Investigating the terminology used to describe Ecstasy
}

\section{Introduction}

In their paper Smith, Moore and Measham (2009) outlined an issue in the undocumented emergence of a new form of Ecstasy known as MDMA powder or crystal. It was noted that this new form could have ramifications not only on under reporting of drug use but also inhibit the work of healthcare professionals working towards harm reduction. The authors comment that the general understanding of the difference between the two terms had yet to be established. Five years on and this is still the case with the relative prevalence and consistency of use of both terms, Ecstasy and MDMA, unknown. A considerable body of literature across a range of disciplines has been written about 'Ecstasy'. However there has been no published articles which addresses the use of the nomenclature, Ecstasy and MDMA, or how these two terms are used. This paper addresses the issue through the use of metadata analysis of a selection of resources; from governmental organizations, academic publications and web-based information sources to establish the use and consistency of both terms.

In popular drug culture there is a unique and specific language which is associated with not only the substances themselves, but also how they are used and the societal context that surrounds them, for example their control status. For each individual compound and class of compounds there is a multitude of names and subsequent terminology or 'slang' with which they are associated. In regards to the terms 'Ecstasy' and MDMA, the term 'Ecstasy' is a colloquial generic brand name whereas the term MDMA is derived from the abbreviation of the chemical compound 3, 4-Methylenedioxymethamphetamine, the psychoactive compound which is found in Ecstasy. The diversity in terminology is not only limited to the language being used to describe the drugs but also to the groups and organisations who make use of this language when discussing drugs and drug use.

One group who actively utilizes the language surrounding drug and drug use is the academic community who study these compounds from a host of different disciplines. These studies range from establishing what effect these chemicals have on the individual to the effect they have on society as a whole. In the context of this paper the academic literature has been evaluated through the preference of the keywords chosen by examining the use of either Ecstasy or MDMA as key words. The second group who make use of the language are the policy makers, governmental organisations and law enforcement agencies (e.g. the United 
Nations Office on Drugs and Crime), whose role it is to evaluate the literature produced by the academic community and then implement it into legislation and subsequently enforce it. The use of the two key terms, Ecstasy and MDMA, by these organisations has also been considered. The key organisation in the United Kingdom which oversees the evaluation of the academic output is the Advisory Council on the Misuse of Drugs (ACMD) whose own use of the two terms is evaluated. The dissemination of the academic and policy information is through a third group of sources who propagate the information about the substances. Included in this group are the healthcare professionals, educational programmes, the media and the internet/web-based resources whose purpose it is to provide information to the general public. It is the output of the last two groups which form the foundation of the comparison for this paper. The last and final group who make use of the language are the general public who rely on the information provided by the other three groups. Their use of language has been evaluated through the analysis of google trends, software which tracks the use of search terms.

What has yet to be established is whether there is cohesion in the language used by these different groups when it comes to reporting on and discussing Ecstasy and MDMA. Both terms have been used synonymously in the past. A thorough investigation of the literature will establish for the first time whether there has been a shift in the frequency with which the two terms are being used and if there has what implications this has with regards to the dissemination of accurate information.

\section{Why the names of drugs are important}

As with any taxonomy there are different classifications under which each substance may fall. The chemical MDMA is part of the Amphetamine-Type Stimulant (ATS) class of substances. This is due to its chemical structure and reported stimulating effects. MDMA's other noted effects mean that it is also a part of a class of substances known as 'empathogens' (Harris et al., 2002).

Illicit drugs do not generally have just one name. In addition to their chemical name they have a number of colloquial synonyms which differ not only by geographical location and also over time. A number of issues can arise when there is a difference and/or overlap in names being used. For example different names can be used for the same compound or the same name can be used for different compounds as is the case with the colloquial term 'Speed' which has been 
used to describe both amphetamine and methamphetamine as can be seen on the website Erowid (https://www.erowid.org).

In the case of the MDMA, it is reported to have gained its infamous moniker, Ecstasy, from an anonymous American dealer in the early 1980s, when it started coming into prevalence in the recreational drug scene;

'Ecstasy was chosen for obvious reasons, because it would sell better than calling it Empathy. Empathy would be more appropriate but how many people know what that means?'

(Pilcher, 2008 pg.24).

Subsequently the term Ecstasy has followed the spread of this substance around the globe until it finally made its way to the British dance scene towards the late 1980s (Karch, 2011). Aided by clear branding stolen from other famous designs the 'Ecstasy' tablet became the third most used drug in Britain (ibid).

Towards the end of the nineties and into the first decade of the new millennium the declining purity and quality of tablets found on the Ecstasy market led to an apparent decline in their use (Cole et al, 2001 and Smith, Moore \& Measham, 2009). This is supported by seizure levels reported; primarily at a national level by the ACMD (2009), at European level as reported by the European Monitoring Council for Drugs and Drug Addiction (EMCDDA) (2004 - 2013), and lastly at a global level as reported by the United Nations Office on Drugs and Crime (UNODC) in their annual World Drug Reports (2004 - 2013). The decline in the use of Ecstasy tablets could have been a reason for the shift or 'rebranding' of the product back to the chemical designation MDMA. The extent of this change will be assessed through the analysis of the use of both terms throughout this paper.

\section{An analysis of the use of language in publications by the UNODC \& EMCDDA}

An analysis was completed to determine the frequency with which the two terms Ecstasy and MDMA have been used within the annual reports from the EMCDDA and the UNODC. These were chosen because these are the two major organisations that report and assess the impact of drugs on society at a global and continental level. The UNODC annually compiles data on 
global drug trends, trafficking, and reported usage which forms the basis of their World Drug Report.

The UNODC's definition of the term Ecstasy states that; 'Ecstasy is a subgroup of drugs which contains MDMA and its analogues' (UNODC, 2013). This infers that the compound MDMA is not to be considered to be directly synonymous with the term Ecstasy, but rather 'Ecstasy' is used as an all encapsulating term for any of the ring-substituted phenethylamines.

The EMCDDA also produce annual reports on the prevalence and use of drugs available in a multitude of languages as pdf documents found on their website. They have two published definitions of Ecstasy. The first description that they use can be found in the annual reports which states:

'Ecstasy refers to synthetic substances that are chemically related to amphetamines...The best-known member of the Ecstasy group of drugs is 3, 4-methylenedioxy-methamphetamine (MDMA), but other analogues are also sometimes found in Ecstasy tablet'

(EMCDDA, 2013, pg51).

The definitions used by both the UNODC and the EMCDDA employ the term 'Ecstasy' as an umbrella term to cover a range of analogous substances. However there is a slight deviation in what definition is used when it comes to the second definition which can be found on the drug profile pages published on the EMCDDA homepage. As part of the EMCDDA's web based information page they provide profiles of a number of substances which are stated as being 'scientifically sound descriptions of drugs' (http://www.emcdda.europa.eu/drug-profiles/mdma). Instead of there being a profile dedicated to the drug 'Ecstasy' there is in its place one for MDMA. On the profile page, the description is given as 'a synthetic substance commonly known as Ecstasy, although the latter term has now been generalised to cover a wide range of other substances' (ibid). The page also states that the most prevalent form the drug is found in is white tablets yet also notes other forms of powders and capsules are found but less commonly. Although both definitions given by the EMCDDA refer to Ecstasy as an encapsulating term for a range of substances there is an apparent change in focus from the term Ecstasy to the term MDMA. This change in focus for the drug profile is of key importance 
since it suggests that there has been a change in use of these two terms with the use of MDMA being more prominent.

This idea was further explored by analysing the frequency with which the two terms, Ecstasy and MDMA have been used by both organisations over a ten year period within their annual reports shown in Figure 1.

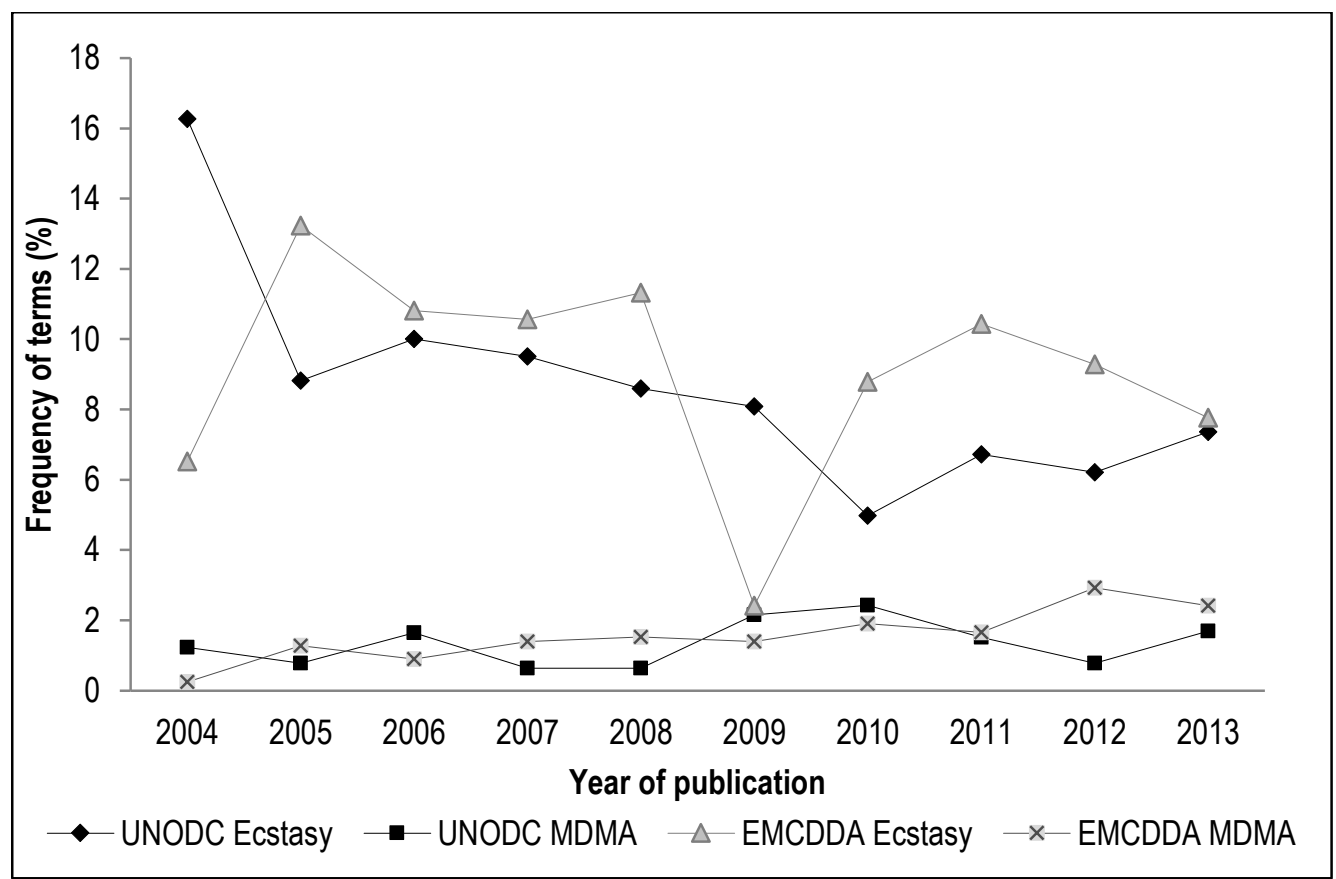

Figure. 1: The frequency of the terms Ecstasy and MDMA used in the annual reports produced by the UNODC World Drug Report and the EMCDDA Annual drug monitoring report.

The data shown in Figure 1 indicates the change over time in the frequency of each term found in the annual reports from both organisations. The frequency was calculated by recording the number of incidences with which both search terms occurred throughout the documents using the Nvivo software. This was then converted to a percentage by dividing the frequency of each term by the total number of times Ecstasy and MDMA appeared within each set of documents, with each set of documents considered as individual data sets. The total number of occurrences is 2189 for the UNODC reports and 868 for the EMCDDA reports.

Up to 2013, there is a clear preference for the term Ecstasy being used by both organisations. This is not unexpected when considering their official descriptions and use of Ecstasy to represent more than merely MDMA in terms of seizures, usage and trafficking. 
One point of interest is the marked decline in the use of the term Ecstasy in the 2009 EMCDDA report and then in 2010 UNODC report. This can be correlated to the lack of availability of MDMA found globally at this time. This deficit was due to the increase focus on the control of safrole which is one of the main precursors for the manufacture of MDMA (UNODC, 2008 available at http://www.unodc.org/unodc/en/frontpage/cambodia-tackles-safrole-oilproduction.html).

Though Ecstasy is the more prevalent term used by the UNODC the frequency with which it is found per report has declined over the last decade. Meanwhile the use of the term MDMA has remained consistent in the World Drug Report. The focus of the EMCDDA's report has varied depending on the prevalence of the drugs found in Europe year on year. As both sets of reports reflect changes in overall drug trends different drugs have become the focus dependant on their relative prevalence and the political focus. The relevance of this data becomes apparent when it is compared to the use of the terms in academic literature and by the web based information sources.

\section{An Academic Perspective}

The study of drugs is of interest to a variety of parties and disciplines and it is important when looking at these substances to differentiate between research on the pure compound and what it is found on the street. A literature search was conducted on two databases of academic journals relating specifically to the study of drugs (Elsevier https://www.elsevier.com/advanced-search and Sage - http://onlne.sagepub.com/). These databases were chosen as both make use of similar online search parameters for their archives which proved advantageous when compiling comparable data. Other databases were investigated but did not contain the same level of discriminative search parameters for the purpose of comparison, namely not being able to limit the data by location. Through the use of databases and restricted search terms a count was conducted of the number of times Ecstasy, MDMA and both terms together were used in the keywords of journal articles.

The keywords are one of the most important factors when searching for and evaluating academic literature. In choosing a key word the author is focusing what the impact and relevance of the article is about into a limited number of words. In choosing to examine the use of Ecstasy and MDMA as key words it filters the journals and articles that mention these 
specific terms without them being the focus of the article in question. Figure 2 illustrates the change over time in the use of the two terms, comparing when they have both been used as keywords and when they have been used separately. Figure 3 shows the difference between when each term has been used individually as a keyword alone.

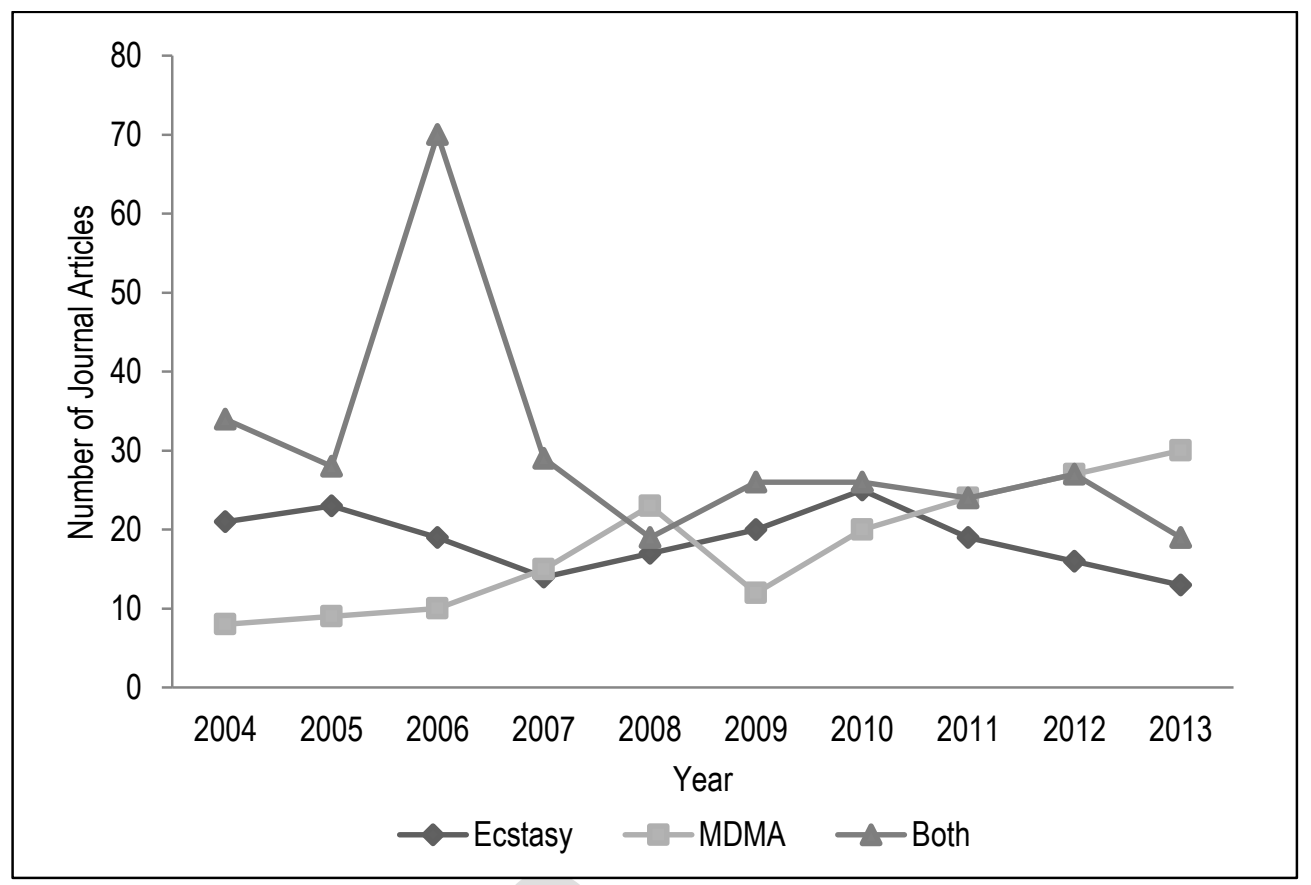

Figure 2:- The frequency of the terms appearing as keywords, together and individually in journal articles from the UK in the academic databases Elsevier \& Sage

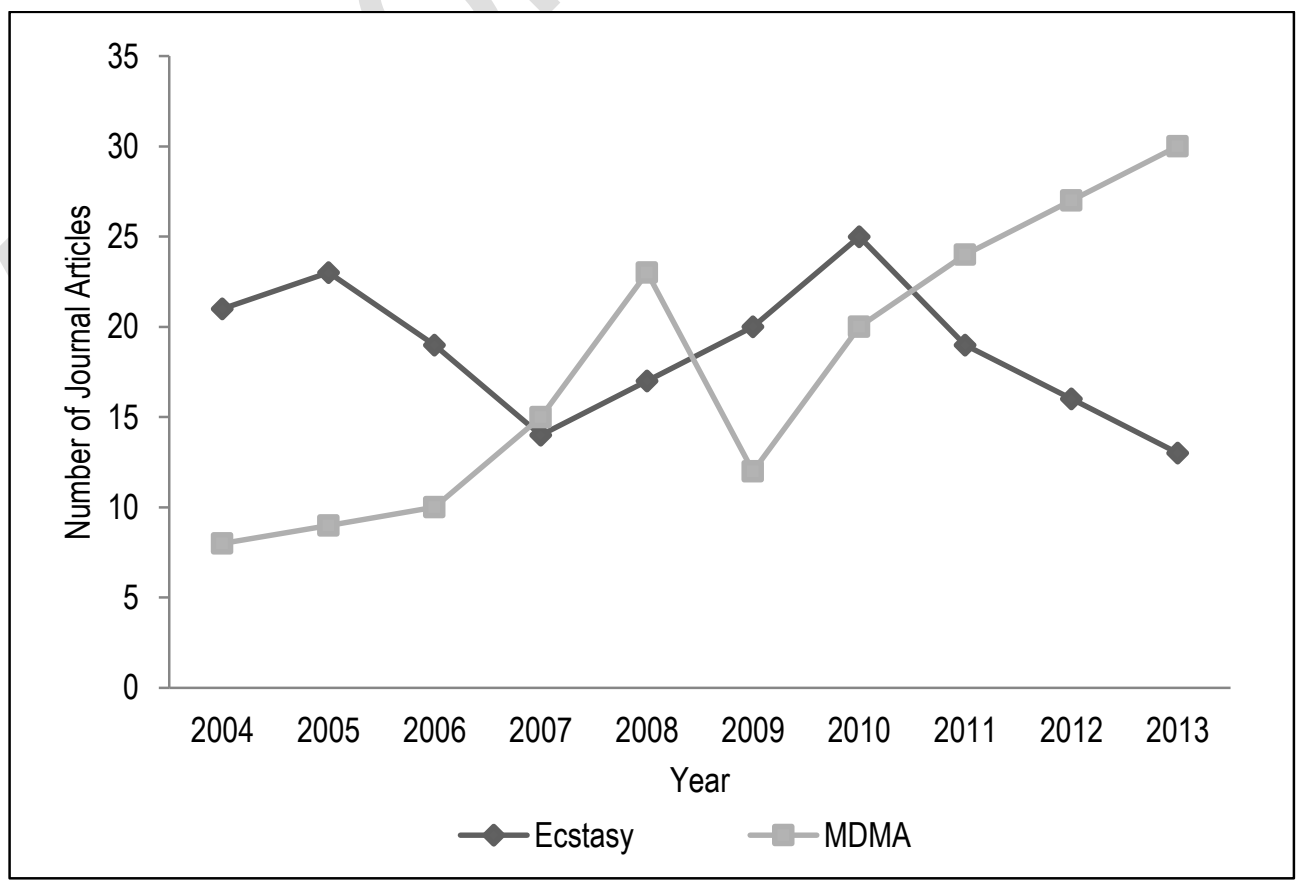

Figure 3:- The frequency with which each word appears individually as a keyword found in journal articles from the UK in the academic databases Elsevier \& Sage 
Figure 2 shows that there was a marked increase in journals which used both terms as key words in 2006; the impact of this is evident in the policy making of the United Kingdom as demonstrated in the correspondences between the Science and Technology Committee (STC) and ACMD. The response published by the ACMD to the STC report states that;

'In view of the high-profile nature of the drug and its apparent widespread usage amongst certain groups, it is surprising and disappointing that the ACMD has never chosen to review the evidence for ecstasy's Class $A$ status... We recommend the ACMD carries out an urgent review of the classification of ecstasy.'

(Rawlins, 2006 pg12)

The recommendation was accepted and the ACMD went on to publish their review in 2009. They acknowledged that MDMA was the most prevalent compound found in Ecstasy. When examining the prevalence of the language used in the review report the authors use the term MDMA 1.5 times more often than that of Ecstasy. This relates to the findings displayed in Figure 3, when the individual use of both terms is considered, as in 2008 the term MDMA is recorded as being used as a keyword more frequently than Ecstasy for the first time.

After the increase in use of the term in 2008, the frequency of the use of the term MDMA falls in 2009. This reflects the findings shown earlier in Figure 1, from the UNODC and the EMCDDA Reports, reflecting the lack of MDMA available globally at this time. However, post 2011 the most prevalent term being used as a keyword in the journals and databases examined is MDMA. There has also been an apparent decline in the number of journals that used both terms as key words as shown in Figure 2.

The findings from this study suggest that that MDMA has replaced the term Ecstasy in the academic vocabulary. This also supports the idea that there may have been a shift in type of Ecstasy being found on the street as suggested by Smith, Moore and Measham (2009). However these findings are contradictory to the conclusions found in Figure 1, which described the usage by both the UNODC and the EMCDDA which maintained the use of the term Ecstasy. The difference between the two can be attributed to the necessity for the global organisations to reflect the use of the term in its broadest sense. 
The review of the academic literature could be considered reductionist as it merely reflects the literature from the UK; however this data is further supported by the analysis of the media, online information sources and search terms stored by Google. To further explore whether there has been a definitive shift in the use of the two terms in the UK a third database was assessed. This was explored by examining the response by the British media, with a specific examination of news stories published by the BBCnews archive.

\section{Ecstasy, MDMA and the Media}

To examine the impact and change of language in the media the frequency with which each term appears in the news stories reported on the BBC news website (www.bbc.co.uk/search/news) was selected as an example to compare to the other sources. The BBC website was chosen due to the similarity in the search function of its archive to that of the journal databases. With the same search parameters being employed allowing for comparable data the findings are shown in Figure 4.

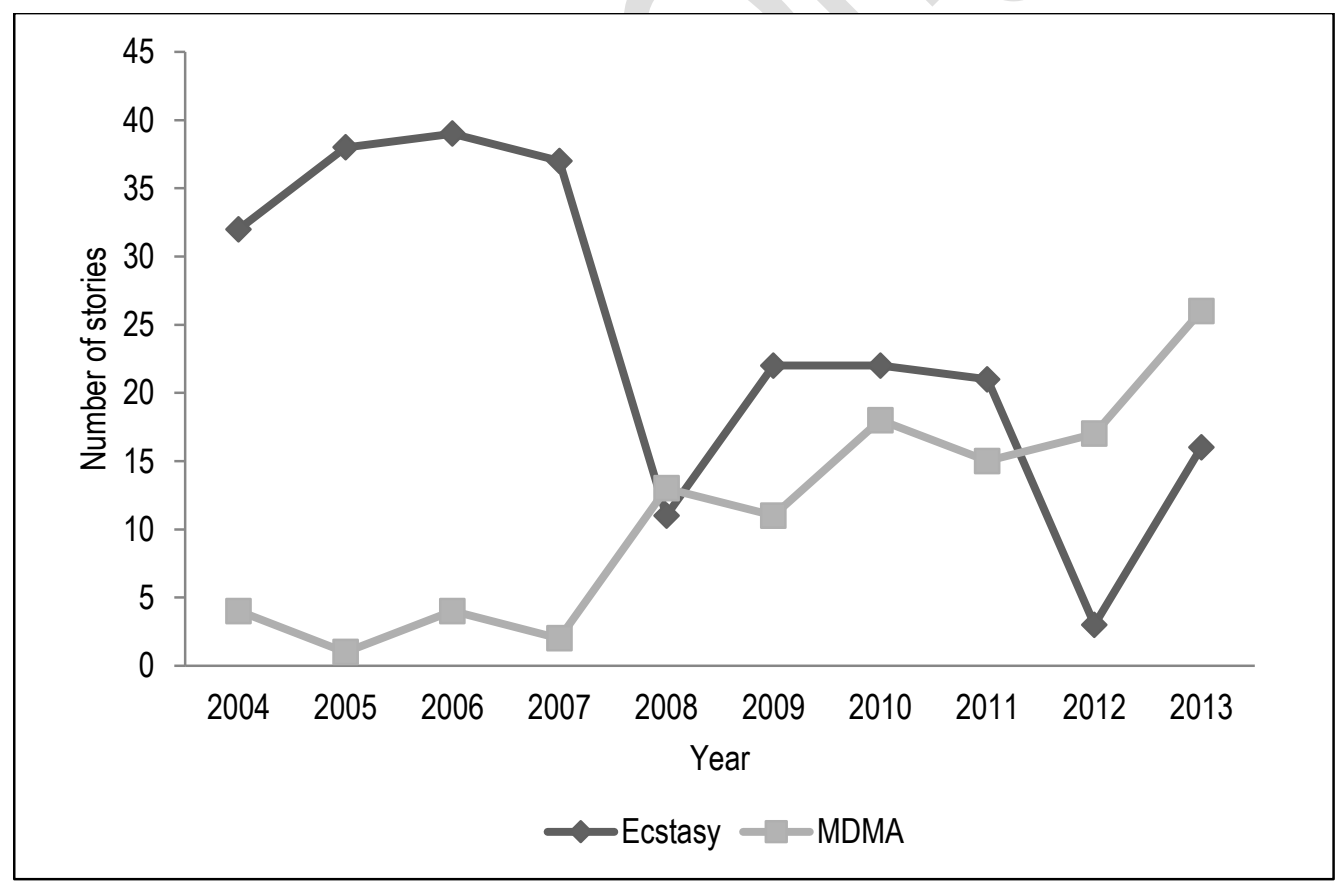

Figure 4: Number of news stories referencing Ecstasy and MDMA as reported by the BBC News Corporation

As with the findings from the academic literature search the data above shows that there has been a definite change in the use of the two terms in the period between 2008 and 2011. There is the same drop in use of the term Ecstasy in 2008 with further usage mirroring the findings reported above. However the term MDMA has increased year on year, until finally surpassing 
the term Ecstasy in 2012, to become the more frequently used term in the subsequent year. This data supports the dominance of the term MDMA over Ecstasy, as found with the academic database results. This suggests that within the UK at least, MDMA is the term that is being used. However the differentiation between the two terms requires further defining as technically they both refer to the same compound. To examine how a differentiation could be achieved the way both terms are used by a number of web-based information sources has been considered.

\section{Web based Information sources}

The lack of consistency in the description of Ecstasy could be an issue for a number of individuals and organizations, including healthcare professionals, drugs educators and law enforcement organisations. This role becomes difficult when the information provided is inconsistent, not only between the political and academic sources, but also when it is at odds with the vast array of internet and web based sources.

One of the most respected independent online sources of drug information is the website Erowid. Similar to the pages found on the EMCDDA's website, Erowid works with academics, medical experts and user based experiences to provide individual pages devoted to psychoactive substances. Parallels can be drawn between Erowid's page and the EMCDDA's, as both choose to use the term MDMA as the focus, with Erowid providing the following description;

'MDMA is one of the most popular recreational psychoactive, most commonly sold in the form of "ecstasy" tablets'

(http://www.erowid.org/chemicals/mdma/mdma.shtml)

Though its vaults provide a vast abundance of information on all things drugs related, Erowid is not considered to be an official drugs educational resource, nor is it specific to the British drug culture, yet a distinction is made by mentioning the form, namely ecstasy being tableted. This could perhaps be the route to differentiation, whereby Ecstasy refers to tableted form and MDMA crystalline. This can be examined further by looking at other web based resources. 
In 2003 the UK government launched the 'Talk to Frank' campaign as a 'standardised educational drugs prevention messages' programme (Smith, Moore \& Measham, 2009, pg.16). As with the EMCDDA, the web-based service provides individualised profiles on the most common recreational drugs found in the UK. However, unlike the profile on the EMCDDA's website TalktoFrank has stuck with the term Ecstasy as the chosen term, with the option for MDMA being redirected to the Ecstasy page (http://www.talktofrank.com/drug/ecstasy). As a part of the profile a description of Ecstasy's appearance is given as;

'Pure ecstasy is a powder made of white crystals, known to chemists as MDMA. Ecstasy is usually sold on the street as tablets, although it's getting more common to see it sold as powder and called by its chemical name, MDMA, or 'crystal'.'

(http://www.talktofrank.com/drug/ecstasy)

Again the form in which the drug is found dictates the name which it is given, Ecstasy to tablets, MDMA to crystal or powdered. Yet the description may cause concern as it suggests that the newer powdered form is 'pure' without the relative purity having been established. If the communication from 'standardised educational message' is that MDMA powder is pure this could mislead users and inhibit harm reduction initiatives. This message is reiterated by the drugs educational charity DrugScope, whose own web based information portal states that;

'Ecstasy is an illegally manufactured drug that usually comes in tablet or capsule form. The chemical name of pure ecstasy is 3, 4 Methylenedioxymethamphetamine or MDMA for short' (http://www.drugscope.org.uk/resources/drugsearch/drugsearchpages/ecstasy.)

Both of these resources provide an explanation that is misleading. With the emergence of these two terms, the perception being promoted is that the term MDMA means "pure". From the purely chemical sense this is true as it is the abbreviation of the longer chemical name. However the term MDMA has been used to effectively rebrand the new powdered and crystal form of this recreational drug. A distinction needs to be made between what is understood as the pure chemical and this new product on the street.

A final information source that provides evidence in the shift in the use of these two terms is the search engine Google. In 2006, the internet giant launched a series of applications, one of 
which was its 'Trends' application (http://www.google.com/trends/), a system which records the frequency with which users search for terms which can then be limited by location and time. To further support the changing of use of these two terms is the data collected from this application displayed in Figure 5.

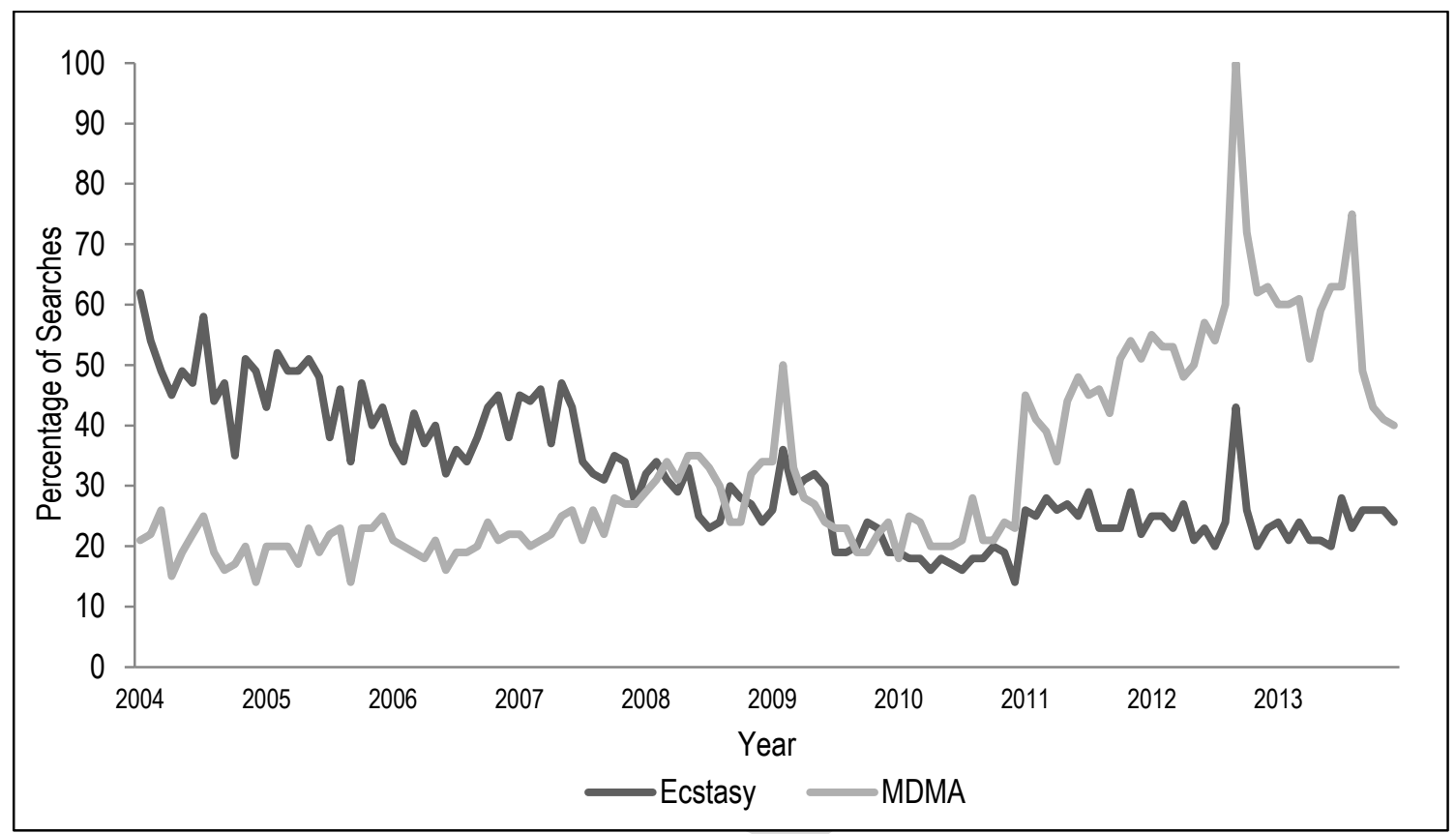

Figure 5: Frequency of searches for both search terms entered into Google Inc.

The data shows the search trends within the UK and reflects a similar pattern to the ones shown in both Figures 3 and 4 . Similar to the findings from both the academic and media searches, it is seen that the term Ecstasy is the most prevalent term being used until 2010 when MDMA began to overtake and become to more dominant term. This supports the notion that not only have the academic community moved away from the use of Ecstasy to describe this recreational drug but so have the general public within the UK.

This data shown in figure 5 could also reflect the change in use and prevalence of the different form of MDMA powder becoming available. This can be explored by looking at the results of the 'Global Drug Survey' run in collaboration with the magazine Mixmag (Mixmag 2010 2012). The survey asks its participants which drugs they have tried. Over the last 5 years, the language they have used to describe the substance MDMA has shifted, in 2010 participants were asked if they had tried Ecstasy or MDMA powder, with both answers being displayed as separate. In 2011 the option Ecstasy (pills or powders) was deployed. However since 2012 the 
Global Drug Survey has just used the term MDMA, omitting the use of the term Ecstasy (Globaldrugsurvey.com, Mixmag 2010, 2011, 2012). This change reflects the findings from the other sectors examined; that the change in language reflects a change in the type of drug being found and used, moving away from tablets towards the powders.

\section{Conclusion}

This paper has examined the different sources and groups concerned with the dissemination of information concerning illicit drugs. What has been shown is a distinct change in the prevalence of use of the term 'MDMA'. It now being used to describe what was once known as 'Ecstasy' in the UK. However this shift in use has not been universal or consistent, as has been shown with the analysis of both the UNODC and the EMCDDA who both still exhibit a preference for the term 'Ecstasy',

The persistence in the use of 'Ecstasy' as the main term used in the annual reports produced by both organizations can be explained due to its encapsulating nature; in this regard it is not a direct synonym for MDMA but rather a descriptive for a group/class of substances - the ringsubstituted phenethylamines. The use may also be explained in the persistent association with the form in which these substances are found, namely as tablets. Both sets of annual reports state that the most prevalent form is that of the 'Ecstasy' pill; however this is not necessarily now the case in the UK.

Recent years have seen the emergence of a new form of powdered and crystalline drug which is sold as 'MDMA' (Smith, Moore \& Measham 2009). There is very little information available to date on the current prevalence of powdered MDMA compared to the tablets, or the relative purity of this new product. Yet the data suggests that the emergence of this new form may be a reason for the change in the use of these two terms. Whilst the term Ecstasy signifies the tablet form, MDMA has come to signify the powdered or crystalline. This change in the language may not only reflect the different types now being found but the prevalence of use of each type.

Another factor that may have impacted not only the shift in terminology but changed the method of substance delivery is the reputation that Ecstasy pills have subsequently gained. Long since the 'heyday' of the eighties and nineties the declining purity of ecstasy tablets is 
well documented (Cole et al, 2001, Parrott, 2004, Smith, Moore \& Measham, 2009,). The decline in purity led to a decline in the popularity and trust in Ecstasy tablets. This precipitated a change in the way that Ecstasy was being sold. Ecstasy is now an imprecise term where once it related to the branding of MDMA pills. It is now associated with a cheap and poor quality product (Smith, Moore \& Measham, 2009) whilst a new product, MDMA powder, has emerged in its place with a reputation for purity.

So why is clarification of the terms necessary? There are a number of stakeholders to whom accurate consistent information is vital. There is much discussion around the need for harm reduction and evidence-led policy when it comes to the discussion around what to do about drug use. The most important issue is to make sure that every party is using the same terminology when describing the same problem, for example if the UNODC claim Ecstasy use is on the decline, a statement based on tablet seizures and yet the Global Drug Survey and other organizations state that MDMA use is on the increase, what are policy makers, law enforcement and the health professionals to use? Admittedly the social reaction in the UK is different to that of the rest of the global population, as the UK is reportedly the largest market for the new psychoactive substances (NPS) in Europe (UNODC, 2013). However it is important to understand the different terms people use when selling products and using them to be able to provide the right information.

There is a need for a consistent use of language and a universal description of illicit substances is important when identifying issues within the recreational drug market at local, regional, national and, indeed, international levels. Is Ecstasy use on the decline or has there just been a shift to using MDMA powders? From a health perspective, when someone claims to have taken Ecstasy, are they talking about a pill or a powder? Is there a reason differentiate between the two? The answer has to be an emphatic "yes", especially from a harm reduction perspective as there is very little information regarding the relative purity of the new powdered MDMA, what it actually contains, and at what concentrations?

There has been a change in the use of language to describe Ecstasy. This change may reflect more than just what people are saying and may actually provide an insight into the change in the type and form of MDMA being used. It may also provide important information for healthcare professionals, educators and law enforcement professionals. 


\section{References}

ACMD, (2009). MDMA ('Ecstasy') A Review of its Harms and Classification under the Misuse of Drugs Act 1971. London: Home Office

Cole, J.C., Bailley, M., Sumnall, H.R., Wagstaff, G.F and King, L.A. (2002), The content of Ecstasy tablets: implications for the study of their long-term effects. Addiction, 97(12), 1531-6.

DrugScope, (2014). Ecstasy [Website] available at:

http://www.drugscope.org.uk/resources/drugsearch/drugsearchpages/ecstasy

EMCDDA, (2004). Annual Report: The State of the drugs problem in the European Union and Norway. Belgium: EMCDDA

EMCDDA, (2005). Annual Report: The State of the drugs problem in Europe. Belgium: EMCDDA

EMCDDA, (2006). Annual Report: The State of the drugs problem in Europe. Belgium: EMCDDA

EMCDDA, (2007). Annual Report: The State of the drugs problem in Europe. Belgium: EMCDDA

EMCDDA, (2008). Annual Report: The State of the drugs problem in Europe. Belgium: EMCDDA

EMCDDA, (2009). Annual Report: The State of the drugs problem in Europe. Belgium: EMCDDA

EMCDDA, (2010). Annual Report: The State of the drugs problem in Europe. Belgium: EMCDDA

EMCDDA, (2011). Annual Report: The State of the drugs problem in Europe. Belgium: EMCDDA 
EMCDDA, (2012). Annual Report: The State of the drugs problem in Europe. Belgium: EMCDDA

EMCDDA, (2013). Annual Report: The State of the drugs problem in Europe. Belgium: EMCDDA

Harris, D., Baggott, M., Mendelson, J.H., Mendeson, J.E. and Jones, R.T (2002). Subjective and hormonal effects of 3, 4 Methylenedioxymethamphetamine (MDMA) in humans.

Pharmacology, 162,396-405

Karch, S. (2011). A Historical Review of MDMA. The Open Forensic Science Journal, 2011, 4, 20-24

Mixmag, (2010). The Mixmag 2010 Drug Survey, [website] London: Mixmag. Available at: http://www.mixmag.net/words/news/the-mixmag-drug-survey-launches

Mixmag, (2011). The Mixmag 2011 Drug Survey, [website] London: Mixmag. Available at: http://www.mixmag.net/words/news/the-mixmag-drug-survey-launches

Mixmag, (2012). The Mixmag 2012 Drug Survey, [website] London: Mixmag Available at: http://www.mixmag.net/words/news/the-mixmag-drug-survey-launches

Parrot, A. (2004). 'Is ecstasy MDMA? A review of the proportion of ecstasy tablets containing MDMA, their dosage levels and the changing perceptions of purity. Psychopharmacology, 173, 234-241

Pilcher, T. (2008). The Incredibly Strange History of Ecstasy, London: Running Press

Rawlins, M. (2006). 'Drug Classification: Making a Hash of it?' Response of the Advisory Council on the Misuse of Drugs (ACMD) to the House of Commons Science and Technology Committee's report. London: ACMD

Smith, Z., Moore, K. \& Measham, F. (2009). MDMA powder, pills and crystal: the persistence of ecstasy and the poverty of policy. Drugs and Alcohol Today, 9(1), 13-19 
UNODC, (2004). World Drug Report. New York: United Nations UNODC, (2005). World Drug Report. New York: United Nations UNODC, (2006). World Drug Report. New York: United Nations UNODC, (2007). World Drug Report. New York: United Nations UNODC, (2008). World Drug Report. New York: United Nations UNODC, (2009). World Drug Report. New York: United Nations UNODC, (2010). World Drug Report. New York: United Nations UNODC, (2011). World Drug Report. New York: United Nations UNODC, (2012). World Drug Report. New York: United Nations UNODC, (2013). World Drug Report. New York: United Nations. 